\title{
Injectable hydrogel as stem cell scaffolds from the thermosensitive terpolymer of NIPAAm/AAc/HEMAPCL
}

This article was published in the following Dove Press journal:

International Journal of Nanomedicine

II September 2012

Number of times this article has been viewed

\author{
Sheng Lian' \\ Yan Xiao' \\ Qingqing Bian' \\ Yu $\mathrm{Xia}^{2}$ \\ Changfa Guo ${ }^{2}$ \\ Shenguo Wang ${ }^{2}$ \\ Meidong Lang' \\ 'Shanghai Key Laboratory of Advanced \\ Polymeric Materials, Key Laboratory \\ for Ultrafine Materials of Ministry \\ of Education, School of Materials \\ Science and Engineering, East China \\ University of Science and Technology, \\ Shanghai, People's Republic of \\ China; ${ }^{2}$ Department of Cardiac \\ Surgery, Zhongshan Hospital, Fudan \\ University and Shanghai Institute of \\ Cardiovascular Diseases, Shanghai, \\ People's Republic of China
}

Correspondence: Yan Xiao Key Laboratory of Advanced Polymeric Materials, Key Laboratory for Ultrafine Materials of Ministry of Education, School of Materials Science and Engineering, East China University of Science and Technology, I 30 Meilong Road, 200237 Shanghai, People's Republic of China

Tel +862 2I 64251764

Fax +86 21 64253916

Email yxiao@ecust.edu.cn

Meidong Lang

Key Laboratory of Advanced Polymeric Materials, Key Laboratory for Ultrafine Materials of Ministry of Education, School of Materials Science and Engineering, East China University of Science and Technology, 130 Meilong Road, 200237 Shanghai, People's Republic of China

Tel +862164253916

Fax +86 21 64253916

Email mdlang@ecust.edu.cn

\begin{abstract}
A series of biodegradable thermosensitive copolymers was synthesized by free radical polymerization with $N$-isopropylacrylamide (NIPAAm), acrylic acid (AAc) and macromer 2-hydroxylethyl methacrylate-poly( $\varepsilon$-caprolactone) (HEMAPCL). The structure and composition of the obtained terpolymers were confirmed by proton nuclear magnetic resonance spectroscopy, while their molecular weight was measured using gel permeation chromatography. The copolymers were dissolved in phosphate-buffered saline (PBS) solution $(\mathrm{pH}=7.4)$ with different concentrations to prepare hydrogels. The lower critical solution temperature (LCST), cloud point, and rheological property of the hydrogels were determined by differential scanning calorimetry, ultraviolet-visible spectrometry, and rotational rheometry, respectively. It was found that LCST of the hydrogel increased significantly with the increasing NIPAAm content, and hydrogel with higher AAc/HEMAPCL ratio exhibited better storage modulus, water content, and injectability. The hydrogels were formed by maintaining the copolymer solution at $37^{\circ} \mathrm{C}$. The degradation experiment on the formed hydrogels was conducted in PBS solution for 2 weeks and demonstrated a less than $20 \%$ weight loss. Scanning electron microscopy was also used to study the morphology of the hydrogel. The copolymer with NIPAAm/AAc/HEMAPCL ratio of 88:9.6:2.4 was bioconjugated with type I collagen for the purpose of biocompatibility enhancement. In-vitro cytotoxicity of the hydrogels both with and without collagen was also addressed.
\end{abstract}

Keywords: thermoresponsive, $N$-isopropylacrylamide, biodegradable, bioreactive

\section{Introduction}

Cardiopathy such as myocardial infarction, a potential cause of heart failure, has become one of the leading causes of morbidity and mortality. ${ }^{1}$ The cardiomyocytes die rapidly without sufficient blood supply when myocardial infarction occurs. Unlike most of the parenchyma cells, the damaged cardiac tissue does not usually recover its normal function and can result in heart failure after the infarction due to the limited capacity of self-repair or regeneration of myocardial tissue. ${ }^{2}$ Accordingly, as one of the most successful methods of restoring the injured myocardium, stem cell therapy has been widely studied in the past few years. ${ }^{3,4}$ Experiments discussed in previous papers demonstrate a beneficial effect on tissue regeneration and function recovery of the infarcted myocardium after transplanting stem cells to the injured area. ${ }^{5-8}$ However, transplantation by direct cell injection cannot attain these results due to low cell retention rate and cell redistribution into other organs, ${ }^{9,10}$ so improvement of cell retention and survival in target tissue presents a big challenge for tissue engineering. To solve these problems, injectable hydrogel was developed as a three-dimensional cell culturing 
matrix with high water absorption capacity in vivo, as has been demonstrated by extensive research in recent years. ${ }^{11}$ This novel biomedical material has attracted wide attention for its tissue-like mechanical property, remarkable biocompatibility and, most important, injectability. This injectable system remains a flowable aqueous solution with prepared cells before injection, but instantly forms a stable hydrogel network when delivered into body tissue with the transplanting cells encapsulated. The hydrogel provides a suitable environment for cell adhesion and growth without preventing the transportation of essential nutrient, which is transferred through the gel network during cell proliferation and differentiation. The diffusion of stem cells is consequently diminished, and the cell retention rate is significantly enhanced. ${ }^{12,13}$ The biomedical applications of injectable hydrogels have been extensively investigated for their remarkable advantages of minimal invasive surgery and independency of the defect's shape and size. ${ }^{14}$ This prospective technology would largely alleviate the suffering of the patient and simplify the implementation of cell transplanting surgery.

So far, both natural macromolecules like collagen, ${ }^{15}$ chitosan, ${ }^{16}$ gelatin, ${ }^{17}$ alginate ${ }^{18}$ and hyaluronic acid ${ }^{19}$ and synthetic polymers such as poly $(N$-isopropylacrylamide $)$ (PNIPAAm), ${ }^{20}$ poly(ethylene glycol)/poly(lactic acid-co-glycolic acid) (PEG/PLGA) copolymers, ${ }^{21}$ poly(ethylene glycol)-poly( $\varepsilon$-caprolactone)-poly(ethylene glycol) (PEG-PCL-PEG) triblock copolymers, ${ }^{22}$ and Pluronic ${ }^{\circledR}$ (PEO-PPO-PEO; BASF Corporation, Ludwigshafen, Germany), ${ }^{23}$ or their combinations ${ }^{24}$ have been utilized to produce injectable hydrogels. As one of the most widely used injectable hydrogels, PNIPAAm is a thermosensitive intelligent material which undergoes a reversible sol-gel transition around $32^{\circ} \mathrm{C}$ in an aqueous condition, converting from flowable solution to hydrogel when heated above its lower critical solution temperature (LCST). ${ }^{25}$ LCST is decided by the hydrophilicity of the polymer chain and can be altered by copolymerizing with other monomers. ${ }^{26}$ These characteristics of tunable fast phase transition and low cytotoxicity make PNIPAAm and its copolymers appropriate materials to be applied in cell encapsulating and proliferation, despite the disadvantage of nonbiodegradability in the body. For example, poly(NIPAAm-co-DBA-co-AAc) has been synthesized and applied as an injectable drug delivery system previously. Experiments have demonstrated that this hydrogel exhibited an LCST of $27^{\circ} \mathrm{C}$ and a swelling ratio of $150 \%$ before degradation. However, mass remaining reduced to 0 in 20 days both in vitro ${ }^{27}$ and in vivo, ${ }^{28}$ due to the hydrolysis of DBA leading to an increase of LCST. The rapid degradation ratio is detrimental to the adhesion and proliferation of the cells. This could be solved by copolymerizing with slow-degrading hydrophobic monomers like LA or $\varepsilon$-caprolactone (CL). Ma et $\mathrm{al}^{29}$ synthesized poly(NIPAAmco-HEMA-co-MAPLA) copolymer and studied the rheology and degradation behavior of its hydrogel. The polymer solution experienced a sol-gel transition at about $20^{\circ} \mathrm{C}$ and completely degraded after 200 days. The storage modulus $\mathrm{G}^{\prime}$ of the hydrogel at $37^{\circ} \mathrm{C}$ by rheology test was only $10,000 \mathrm{~Pa}$, which is considered insufficient to apply as a cell scaffold. ${ }^{29}$

In previous works, poly(NIPAAm-co-AAc-co-HEMA-gPCL) was synthesized to form $\mathrm{pH}$-induced thermosensitive and biodegradable micelles as a controlled DOX release system. ${ }^{30}$ However, this copolymer had not been studied as an injectable system. In this paper, a series of copolymers were designed to achieve desirable LCST, high storage modulus, slow degradation rate, and good biocompatibility using NIPAAm, AAc, and macromer 2-hydroxylethyl methacrylate-poly( $\varepsilon$-caprolactone) (HEMAPCL), where NIPAAm provides the thermal sensitivity of the hydrogel, HEMAPCL the biodegradable function, and AAc is used to enhance the hydrophilicity and adjust the LCST. Both NIPAAm content and AAc/HEMAPCL ratio were altered to investigate their impacts on LCST, rheology, and water absorption. Their degradability and cytotoxicity were also studied.

\section{Material and methods Materials}

NIPAAm (99\%, Aldrich) was purchased from Shanghai Wujing Chemical Co, purified by recrystallization in hexane, and vacuum dried for 2 days before use. Acrylic acid (AAc) was distilled under reduced pressure. CL (99.5\%) was purchased from Aldrich, dried by $\mathrm{CaH}_{2}$ and purified by distillation. Benzoyl peroxide (BPO) was recrystallized in methylene dichloride and vacuum dried before use. 2-Hydroxyethyl methacrylate (HEMA) was purchased from Aldrich and used after distilling under reduced pressure at $130^{\circ} \mathrm{C}$. 1,4-Dioxane was dried with $\mathrm{MgSO}_{4}$ overnight, refluxed at $115^{\circ} \mathrm{C}$ for 2 days and distilled under reduced pressure. Acid-soluble type I collagen was purchased from Aldrich and used as received. 1-Ethyl-3(3-dimethyl-aminopropyl)-1-carbodiimide hydrochloride (EDC), $N$-hydroxysuccinimide (NHS), and stannous 2-ethylhexanoate $\left[\mathrm{Sn}(\mathrm{OCt})_{2}\right]$ were purchased from Shanghai Jingchun Reagent Co, Ltd, and used as received. All other 
reagents and solvents were obtained from Shanghai Chemical Reagent Co, Ltd, and used without further purification.

\section{Synthesis of HEMAPCL macromer}

HEMA and CL were added to a flask with a mole feed ratio of 1:5. The flask was sealed by a rubber plug, and stannous octoate in $1 \mathrm{~mL}$ toluene was injected subsequently $(1 \mathrm{~mol} \%$ with respect to HEMA). The mixture was reacted at $110^{\circ} \mathrm{C}$ for 3 hours under vacuum, and then dissolved in tetrahydrofuran (THF), precipitated in cool ethyl ether and maintained at $0^{\circ} \mathrm{C}$ overnight. The precipitate was obtained by filtration and dried in a vacuum oven overnight.

\section{Synthesis of poly(NIPAAm-co- AAc-co-HEMAPCL)}

Monomers of NIPAAm, AAc, and HEMAPCL were dissolved in 1,4-dioxane with different feed ratios to form $10 \mathrm{wt} \%$ monomer solutions. The degassed initiator BPO $\left(7.9 \times 10^{-3} \mathrm{~mol} / \mathrm{mol}\right.$ with respect to monomer $)$ was subsequently added to the flask. The flask was then sealed, and the solution was stirred under vacuum for 20 minutes. The flask was heated to $70^{\circ} \mathrm{C}$ and maintained for 24 hours to complete the polymerization. Afterwards, the solution was cooled to room temperature, diluted by THF, precipitated in excessive diethyl ether, filtered, and dried at $40^{\circ} \mathrm{C}$ in a vacuum oven overnight. The product was then precipitated twice from THF into petroleum ether and vacuum dried at $40^{\circ} \mathrm{C}$ for 24 hours.

\section{Bioconjugation with collagen}

The NIPAAm/AAc/HEMAPCL feed ratio of 88:9.6:2.4 copolymer was used to conjugate type I collagen. Stoichiometric amounts of this copolymer were dissolved in desiccative $N, N$-dimethylfomamide (DMF) in a $100 \mathrm{~mL}$ flask where EDC and NHS (20.83 mol\% with respect to the carboxylic acid group) were added $\left(\mathrm{n}_{\mathrm{EDC}}: \mathrm{n}_{\mathrm{NHS}}=4: 1\right)$ subsequently. The flask was sealed, and the reaction was completed by stirring at room temperature for 48 hours. The mixture was then precipitated in warm water at $50^{\circ} \mathrm{C}$ twice, filtered, and the resulting product was frozen and lyophilized for 2 days at $-50^{\circ} \mathrm{C}$.

After the synthesis of NIPAAm/AAc/NHS/HEMAPCL copolymer, the hydrogel and collagen bioconjugate was prepared by mixing hydrogel copolymer solution with type I collagen. The copolymer with NHS group was dissolved in phosphate buffered saline (PBS) $(\mathrm{pH}=7.4)$ at $4^{\circ} \mathrm{C}$ to form a $15 \mathrm{wt} \%$ solution. The defined amount of type I collagen ( $4 \mathrm{wt} \%$ in acetic acid) was neutralized with small aliquots of
2.0 M sodium hydroxide solution. The final collagen solution was added to the copolymer solution, and the collagen content in the hydrogel was $3 \mathrm{wt} \%$ with respect to the copolymer. After a thorough mixing, the mixture was set at $4^{\circ} \mathrm{C}$ overnight. The final mixture was diluted with deionized water and subsequently purified by dialysis against pure water (molecular weight cutoff: 14,000). Last, water was removed by lyophilization.

\section{Characterization of copolymers}

The proton nuclear magnetic resonance ( ${ }^{1} \mathrm{H}$ NMR) spectra were recorded on a Bruker AM 400 spectrometer at $300 \mathrm{MHz}$, using $\mathrm{CDCl}_{3}$ or DMSO-d6 as the solvent and tetramethylsilane as the internal standard. For HEMAPCL macromonomer, deuterated chloroform $\left(\mathrm{CDCl}_{3}\right)$ was used as the solvent. For poly(NIPAAm-co-AAc-co-HEMAPCL) copolymers with and without collagen, DMSO-d6 was used as the solvent. Fourier transform infrared (FTIR) spectrum of the conjugated copolymer was obtained from a Magna-IR 550 spectrometer (Nicolet Instruments, Madison, WI) at room temperature.

Molecular weight of the copolymers was quantified using gel permeation chromatography (GPC) equipped with Waters 1515 HPLC pump and Waters 2414 differential refractometer. HPLC-grade THF was used as the eluent when $0.1 \mathrm{~mL}$ copolymer solution $(2 \mathrm{mg} / \mathrm{mL})$ was injected. Monodisperse polystyrene was used as standards for calibration.

\section{Gelation experiment and injectability test of the hydrogels}

The sol to gel phase transition behavior of the NIPAAm/ AAc/HEMAPCL copolymers in aqueous medium was determined by the tube-inverting method using a $5 \mathrm{~mL}$ glass vial. ${ }^{31}$ In brief, the copolymers were dissolved in PBS solution at a given concentration at $4^{\circ} \mathrm{C}$ to form $1 \mathrm{~mL}$ solutions of copolymers, which were subsequently heated from $20^{\circ} \mathrm{C}$ to $37^{\circ} \mathrm{C}$ in a water bath with an increment of $2^{\circ} \mathrm{C}$. The vials were kept at each temperature for 10 minutes. Each sample was regarded as a "gel" in the event of no flow being observed within 1 minute by inverting the vial. Injectability of the copolymer solution was tested by injecting a $15 \mathrm{wt} \%, 4^{\circ} \mathrm{C}$ solution through a 26 gauge needle which is widely used in the biomedical injection.

\section{Thermal analysis}

The purified copolymers were dissolved in PBS solution $(\mathrm{pH}=7.4)$ at $4^{\circ} \mathrm{C}$ to form solution with a concentration of 
$15 \mathrm{wt} \%$ and measured by differential scanning calorimetry (DSC) (DSC-60; Shimadzu) with a scanning rate of $5^{\circ} \mathrm{C} / \mathrm{min}$ over a range of $10^{\circ} \mathrm{C}-70^{\circ} \mathrm{C}$. The temperature at the maxima of the endothermic peak was considered as the LCST. All the copolymer solutions were tested. To determine the cloud points (CPs) of copolymer solutions with different concentrations, optical absorbance of the solutions was measured by a Lambda Bio40 UV vis spectrometer (Perkin-Elmer) using UV absorbance at $500 \mathrm{~nm}$. The N88-A4 sample was dissolved in PBS with different volumes $(2.5,5.0,7.5$, and $10.0 \mathrm{wt} \%)$ at $4^{\circ} \mathrm{C}$. Prior to measurements, the quartzose cuvette filled with copolymer solution was thermostated in a refrigerated circulator bath for 5 minutes at different temperatures from $20^{\circ} \mathrm{C}$ to $39^{\circ} \mathrm{C}$. Absorbance and $\mathrm{CP}$ at various temperatures were then measured.

\section{Rheological analysis of the hydrogels}

The dynamic rheology was measured on an RS600 rotational rheometer (Thermo Hakke, GE) in oscillatory mode. Double concentric cylinder geometry (20 mm diameter) with a gap of $1 \mathrm{~mm}$ was used to measure dynamic viscoelastic parameters as functions of the temperature. The samples were prepared in a PBS solution with a concentration of $15 \mathrm{wt} \%$ at $4^{\circ} \mathrm{C}$ and temperature sweeps were performed from $13^{\circ} \mathrm{C}$ to $40^{\circ} \mathrm{C}$ with a heating rate of $1^{\circ} \mathrm{C} / \mathrm{min}$. Viscosity ( $\left.\eta\right)$ and the storage modulus $\left(\mathrm{G}^{\prime}\right)$ were measured at a frequency of $1 \mathrm{~Hz}$ and controlled strain of $1 \%$. The strain was kept as low as possible to minimize the influence of disruption of the hydrogel network in order to obtain the linear viscoelastic performance.

\section{Hydrogel degradation and water content test}

Hydrogel degradation at $37^{\circ} \mathrm{C}$ in PBS was measured by weight loss over a 2 week period. The specified volume of $15 \mathrm{wt} \%$ copolymer solution was added into a teflon mould. The mould was placed in a $37^{\circ} \mathrm{C}$ incubator for gelation, and the formed gel was maintained for 2 hours. The stable hydrogel was then taken out and cut at $37^{\circ} \mathrm{C}$. The pieces were quickly frozen in liquid nitrogen, lyophilized immediately for 2 days at $-50^{\circ} \mathrm{C}$, after which dry samples $(\sim 20 \mathrm{mg})$ were weighed $\left(\mathrm{w}_{0}\right)$. A 24-well plate was used as the degradation vessel, where an equal volume of prewarmed PBS was added. The degradation was conducted at $37^{\circ} \mathrm{C}$. The samples were taken at defined intervals, gently wiped with tissue paper, and weighed $\left(\mathrm{w}_{1}\right)$. The hydrogel was then frozen in liquid nitrogen and lyophilized for 2 days before being weighed again $\left(\mathrm{w}_{2}\right)$. The water content was defined as the normalized difference between the wet mass $\left(\mathrm{w}_{1}\right)$ and dry mass $\left(\mathrm{w}_{2}\right)$ of the hydrogel.

$$
\text { Water content }(\%)=100 \times\left(\mathrm{w}_{1}-\mathrm{w}_{2}\right) / \mathrm{w}_{2}
$$

The weight remaining was calculated as:

$$
\text { Weight remaining }(\%)=\mathrm{w}_{2} / \mathrm{w}_{0} \times 100
$$

At least three samples were evaluated for each hydrogel type.

\section{Hydrogel morphology study}

Morphologies of dehydrated NIPAAm/AAc/HEMAPCL hydrogels and pure PNIPAAm were observed by utilizing scanning electron microscopy (SEM). The hydrogels were prepared as above and then immersed into liquid nitrogen and lyophilized at $-50^{\circ} \mathrm{C}$. Each cross-section of hydrogel was gold-coated and viewed using a JSM-6330F SEM (JEOL, Peabody, MA) operated at $10 \mathrm{kV}$ accelerating voltage.

\section{Cell viability test}

The cell viability of the copolymers with the same NIPAAm content and the bioconjugated copolymer was measured by Cell Counting Kit-8 (CCK-8) method. Rat bone marrow stem cells (BMSCs) were obtained from the Department of Cardiac Surgery, Zhongshan Hospital, Fudan University. The BMSCs were maintained in Dulbecco's Modified Eagle's Medium with 20\% fetal bovine serum, $100 \mathrm{U} / \mathrm{mL}$ penicillin, and $100 \mu \mathrm{g} / \mathrm{mL}$ streptomycin $\left(37^{\circ} \mathrm{C}, 5 \% \mathrm{CO}_{2}\right)$, and split every $2-3$ days. To assay the cell viability, $100 \mu \mathrm{L}$ of cell suspensions (5000 cells/well) were dispensed in a 96-well plate and pre-incubated for 24 hours in a humidified incubator $\left(37^{\circ} \mathrm{C}, 5 \% \mathrm{CO}_{2}\right)$, after which $10 \mu \mathrm{L}$ of copolymer dilute solution was added to each well. The plate was incubated for 96 hours in the incubator, and then $10 \mu \mathrm{L}$ of CCK-8 solution was added to each well of the plate before another 2 hours of BMSC culture. Finally, the cytotoxicity was measured $(n=3)$ at absorbance of $450 \mathrm{~nm}$ using a microplate reader, and the viable rate was calculated by the following equation:

$$
\text { Viable rate }=\mathrm{OD}_{\text {degraded }} / \mathrm{OD}_{\text {control }} \text {, }
$$

where $\mathrm{OD}_{\text {control }}$ was obtained in the absence of the copolymer. 


\section{Results and discussion}

\section{Synthesis of macromer and copolymer}

The macromer HEMAPCL was synthesized by ring-open polymerization of $\mathrm{CL}$ in the presence of 2-hydroxyethyl methacrylate as initiator and stannous octoate as catalyst (Scheme 1A). The product was confirmed by ${ }^{1} \mathrm{H}$ NMR (Figure 1) with evidence of proton peaks from the HEMA residue (a, b, c, d, and e) and PCL segment (f, g, h, and i). The degree of polymerization (DP) of CL in HEMAPCL was calculated by the ratio of the integrals of methylene peak in $\mathrm{CL}$ at $2.3 \mathrm{ppm}$ (f) and those of the double-bond peak in HEMA at $5.6 \mathrm{ppm}$ (b). The DP of HEMAPCL was 10.1, which was about twice the CL/HEMA feed ratio. It was ascribed to the precipitation in ethyl ether, which was soluble for short HEMAPCL chains.

The poly(NIPAAm-co-AAc-co-HEMAPCL) copolymers were synthesized by free radical polymerization using BPO as initiator according to Scheme 1B. Figure 2 shows the typical ${ }^{1} \mathrm{H}$ NMR spectrum of the copolymers. In Figure 2, the copolymer with NIPAAm/AAc/HEMAPCL feed ratio of 88:9:3 demonstrates characteristic proton peaks of NIPAAm units (a, b, h, c, and $\mathrm{k}$ ), AAc units (c and k), and HEMAPCL units ( $\mathrm{d}$, e, f, g, i, $\mathrm{j}, \mathrm{k}$, and $\mathrm{l}$ ), without the observation of a double-bond peak.

A series of thermosensitive copolymers were prepared by varying the molar ratio ( $\mathrm{R}$ ratio) of the hydrophilic monomer AAc and the hydrophobic macromer HEMAPCL
(N88-A2, N88-A3, and N88-A4) and the proportion of NIPAAm (N82-A3 and N94-A3) as listed in Table 1. Actual copolymer compositions were calculated based on the relative intensity of characteristic peaks of each monomer in ${ }^{1} \mathrm{H}$ NMR spectrum. NIPAAm was determined by the signal of amido bond (b) from 3.70 to $3.95 \mathrm{ppm}$, while HEMAPCL content was calculated by the integration of the sharp peak at $2.32 \mathrm{ppm}$ (e), which belongs to the methylene protons $\left(-\mathrm{OC}-\mathrm{CH}_{2}-\right)$ of $\mathrm{CL}$ units. AAc ratio was obtained by the subtraction of the integrations of the methine peak from 1.80 to $2.21 \mathrm{ppm}$ (c) and the amido bond peak (b). It was found that all of the copolymers had the composition and the hydrophilic/hydrophobic $\mathrm{R}$ ratio consistent with the feed ratio. As listed in Table 1, GPC results showed that the copolymers had molecular weights around 20,000 $\mathrm{Da}$. The change of molecular weight could be related to the dispersive viscosity of the reaction system, which might lead to different chain termination. The difference of the initiator efficiency with the monomers might also have influence.

\section{Sol-gel transition analysis}

All the copolymers with designed composition were dissolved in cool PBS solution ( $\mathrm{pH}=7.4$ ), with a concentration of $15 \mathrm{wt} \%$ at $4^{\circ} \mathrm{C}$. The solutions turned into hydrogels within 30 seconds when placed in a $37^{\circ} \mathrm{C}$ water bath. The influence of concentration on the sol-gel transition behavior

A
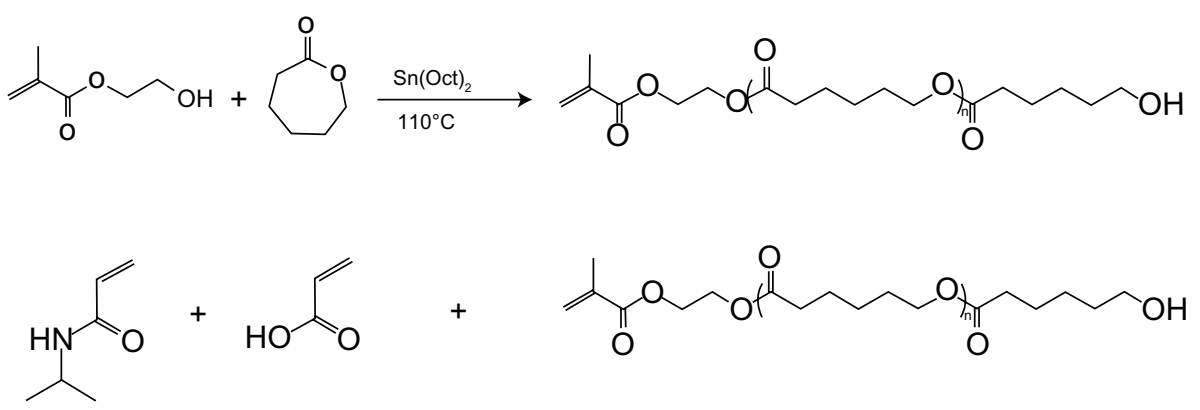

B
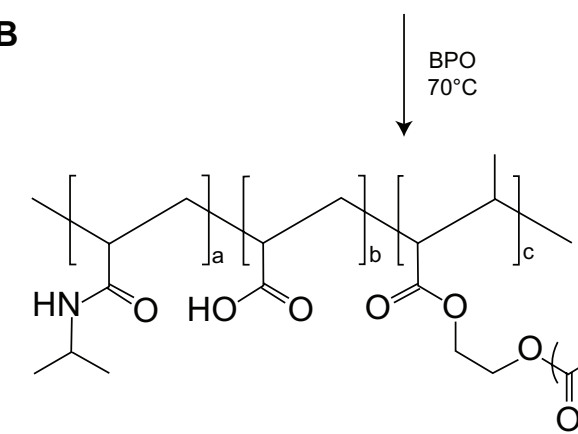

Scheme I Synthesis of the poly(NIPAAm-co-AAc-co-HEMAPCL) copolymer.

Abbreviations: AAc, acrylic acid; BPO, benzoyl peroxide; HEMAPCL, 2-hydroxylethyl methacrylate-poly( $\varepsilon$-caprolactone); NIPAAm, N-isopropylacrylamide. 


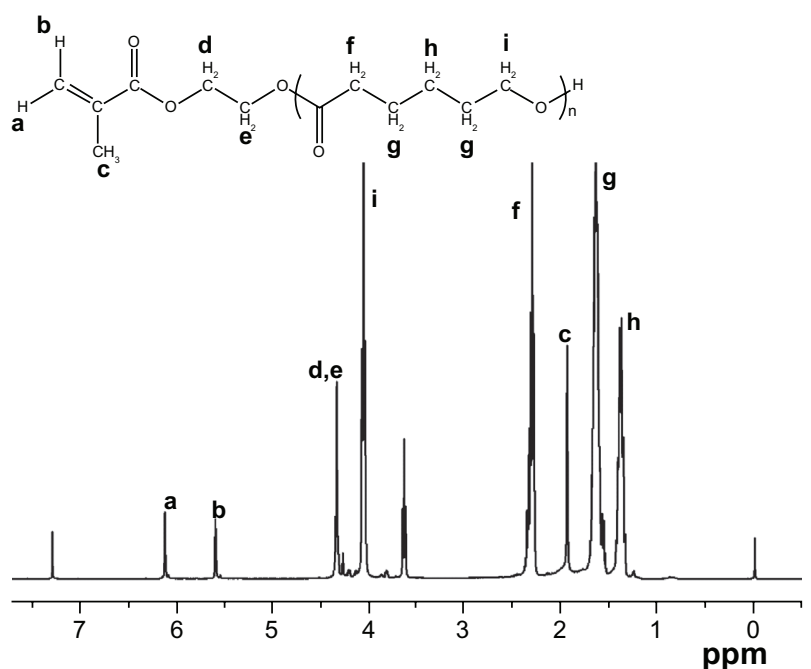

Figure I Proton nuclear magnetic resonance spectrum of the HEMAPCL macromer with the HEMA/CL feed ratio of I:5.

Abbreviations: HEMAPCL, 2-hydroxylethyl methacrylate-poly(e-caprolactone); $\mathrm{CL}$, $\varepsilon$-caprolactone.

was studied in Table 2. The results indicated that all of the copolymer solutions with various feed ratios and concentrations could form stable hydrogels at $37^{\circ} \mathrm{C}$ and turn to transparent solution instantly when cooled to room temperature, except the $5 \mathrm{wt} \%$ N88-A2 solution. This solution failed to form hydrogels and precipitated to form white suspensions at $37^{\circ} \mathrm{C}$. This behavior might be attributed to an excess of hydrophobic HEMAPCL which led to a high density of crosslink sites on each copolymer chain and a high tendency of agglomeration during the hydrophobic association, thus

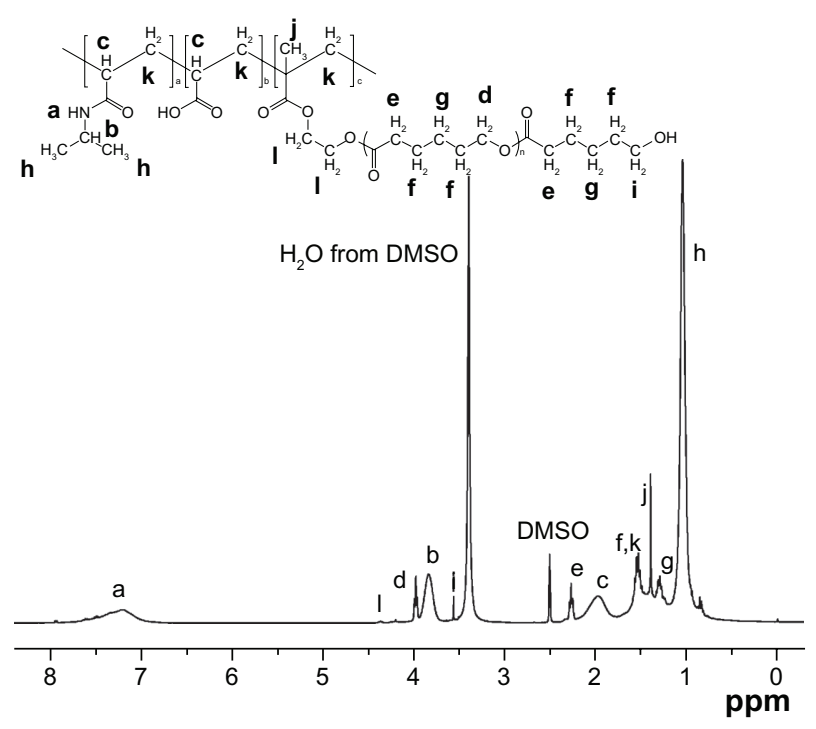

Figure 2 Proton nuclear magnetic resonance spectrum of the NIPAAm/AAc/ HEMAPCL (88:9:3) copolymer.

Abbreviations: AAc, acrylic acid; DMSO, dimethyl sulfoxide; HEMAPCL, 2-hydroxylethyl methacrylate-poly( $\varepsilon$-caprolactone); NIPAAm, $\mathrm{N}$-isopropylacrylamide. preventing effective gel formation. ${ }^{21}$ Comparing the gelation behavior of copolymer with different concentrations, gelation occurred faster for those with higher concentration. However, there was no significant difference in the gelation time among the hydrogels with different monomer composition.

LCST is another important factor which affects the sol-gel transition behavior. The transition temperatures of copolymer solutions with different compositions were characterized by DSC as presented in Table 1. Each copolymer showed an LCST well below $37^{\circ} \mathrm{C}$, ranging from $28.4^{\circ} \mathrm{C}$ to $31.2^{\circ} \mathrm{C}$, varying with the copolymer composition. It has been reported previously that the introduction of hydrophobic components may decrease the LCST of PNIPAAm, resulting from the facilitation of the dehydration of copolymer chains. ${ }^{32}$ Comparing the copolymers of N82-A3, N88-A3, and N94-A3, it could be perceived that the LCST increased remarkably with an increase of the NIPAAm content when the $\mathrm{R}$ ratio (AAc/HEMAPCL ratio) was kept constant. In contrast, when copolymers had the same NIPAAm content ( $88 \%$ mole ratio), increasing the $\mathrm{R}$ ratio appeared to slightly increase the LCST. Thus, under experimental conditions, LCST was more sensitive to the NIPAAm proportion than to the $\mathrm{R}$ ratio. Compared with N88-A4 solution, the hydrogen bonding of N94-A3 solution between copolymer molecule chain and water molecule would be broken at higher temperature for phase separation and gelation..$^{33}$ It was demonstrated that the NIPAAm units within the molecule chain showed dominant influence on the copolymer's LCST.

To evaluate temperature-dependent gelation behavior of the hydrogel solutions, the storage modulus $\left(\mathrm{G}^{\prime}\right)$ and the viscosity $(\eta)$ were measured as a function of temperature. Figures 3 and 4 show the rheological results obtained during the sol-gel transition of the hydrogel solutions (15 wt\%). Taking N88-A4 as an example, the viscosity and storage modulus values increased rapidly at approximately $28^{\circ} \mathrm{C}$, which exhibited the occurrence of the transition from liquid-like state to elastic gel-like state. With increasing temperature, the viscosity and storage modulus reached a plateau at $32^{\circ} \mathrm{C}$, indicating that the network structure of the hydrogel was completely formed by dehydration of the copolymer chain. The sol-gel transition temperature was defined as the temperature at which the storage modulus $\left(\mathrm{G}^{\prime}\right)$ increased rapidly and reached a plateau. After that, $G^{\prime}$ and $\eta$ remained constant, illustrating that a stable gel was formed. ${ }^{34}$ Similar curves were obtained for the copolymers with the same NIPAAm proportion and those with the same $\mathrm{R}$ ratio respectively. 
Table I Characteristics of NIPAAm/AAc/HEMAPCL copolymers synthesized by free radical polymerization

\begin{tabular}{|c|c|c|c|c|c|c|c|c|c|c|}
\hline \multirow[t]{2}{*}{ Copolymer } & \multicolumn{4}{|c|}{ Feed ratio (mol\%) } & \multicolumn{4}{|c|}{ Composition (mol\%) } & \multirow[t]{2}{*}{$M_{n}^{d}$} & \multirow[t]{2}{*}{$\operatorname{LCST}^{\mathrm{e}}\left({ }^{\circ} \mathrm{C}\right)$} \\
\hline & NIPAAm & AAc & HEMAPCL & $\mathbf{R}^{\mathbf{b}}$ & NIPAAm & AAc & HEMAPCL & $\mathbf{R}$ & & \\
\hline N88-A2 & 88 & 8 & 4 & $2: 1$ & 85.9 & 9.7 & 4.4 & $2.2: 1$ & 20289 & 28.7 \\
\hline N88-A3 & 88 & 9 & 3 & $3: 1$ & 86.9 & 9.6 & 3.5 & $2.7: 1$ & 24607 & 29.2 \\
\hline N88-A4 & 88 & 9.6 & 2.4 & $4: 1$ & 87.6 & 9.9 & 2.5 & 4.0:1 & 14542 & 29.7 \\
\hline N82-A3 & 82 & 13.5 & 4.5 & $3: 1$ & 82.0 & 13.6 & 4.4 & $3.1: 1$ & 14759 & 28.4 \\
\hline N94-A3 & 94 & 4.5 & 1.5 & $3: 1$ & 91.6 & 6.3 & 2.1 & 3.0:1 & 20778 & 31.2 \\
\hline
\end{tabular}

Notes: aThe copolymers were named in the form of N "number of NIPAAm content"-A "ratio of AAc and HEMAPCL"; 'R is the mole ratio of the hydrophilic group and the hydrophobic group $\left(R=n_{A A C} / n_{\text {HEMAPCL }}\right)$; 'mole composition of copolymers were calculated from 'H NMR results; 'the $M_{n}$ was determined using GPC; 'LCSTs of the hydrogels were measured by DSC, with the concentration of $15 \mathrm{wt} \%$.

Abbreviations: 'H NMR, proton nuclear magnetic resonance; AAc, acrylic acid; DSC, differential scanning calorimetry; GPC, gel permeation chromatography; HEMAPCL, 2-hydroxylethyl methacrylate-poly(E-caprolactone); LCST, lower critical solution temperature; $M_{n}$, number average molecular weight; NIPAAm, N-isopropylacrylamide.

As shown in Figure 3, with the NIPAAm content kept at $88 \mathrm{~mol} \%$, higher R ratio (ratio of AAc/HEMAPCL) led to much lower $\mathrm{G}^{\prime}$ whether before or after the sol-gel transition and higher transition temperature, which corresponds with the DSC results. The storage modulus $\mathrm{G}^{\prime}$ is strongly affected by the cross-linking density. Hence, the reduction of the storage modulus is probably related to the lower cross-linking density in the hydrogel with higher R ratio, such as N88-A4, which exhibited a looser network structure above LCST. In contrast, when the $\mathrm{R}$ ratio was fixed at 3:1, increasing NIPAAm content had no significant influence on the rheological curves apart from an increase in the transition temperature. Transition temperature also varies with LCST as shown in Table 1. As mentioned earlier, it was the hydrogen bonding between water molecules and NIPAAm units that provided the copolymer solubility in PBS solution at room temperature. However, for the copolymer solution with larger NIPAAm proportion, higher temperature was needed to break the hydrogen bonding and form hydrogel by hydrophobic interaction when heated. As illustrated in Figure 3, all of the formed gels showed a storage modulus of over $80,000 \mathrm{~Pa}$ under dynamic shear stress, which revealed that copolymers with all the compositions were tough enough to be applied as cell scaffold material for myocardial tissue..$^{35}$ With more physical crosslinker HEMAPCL inside the network structure, the hydrogel exhibits better mechanical properties after gelation.
The viscosity of the copolymer solution during heating is presented in Figure 4. It was seen that the viscosity of the solution decreased slightly with an increase of temperature below LCST. Compared with Figure 3, the change in the copolymer storage modulus curves with various feed ratio are consistent with that of the viscosity curves. Although higher HEMAPCL content provided better storage modulus for hydrogels, the decline of $\mathrm{R}$ ratio in the feed gave the copolymer solution a higher viscosity at room temperature and appeared to make it more difficult to inject, as demonstrated in Figure 4. Owing to the strong hydrophobicity which hindered the motion of the copolymer chains in the aqueous solution, it was found that the viscosity of N88-A2 copolymer solution was over $30 \mathrm{~Pa} \cdot \mathrm{s}$ at room temperature. Such high viscosity is not feasible for injection. ${ }^{36}$ The injectability test also demonstrated that all of the samples could be injected through a 26 gauge needle with a concentration of $15 \mathrm{wt} \%$, except N88-A2. Moreover, there was no significant evidence that the viscosity of the copolymer solution was affected by NIPAAm content.

Among all the synthesized copolymers, N88-A4 should be considered the most suitable copolymer for cell scaffold, having the character of fast phase transition behavior, sufficient gel modulus, and best fluidity. Accordingly, optical absorbance of N88-A4 copolymer was measured to investigate the LCSTs of hydrogel copolymer solutions

Table 2 Effects of solution concentration and composition on hydrogel formation behavior

\begin{tabular}{|c|c|c|c|c|c|c|c|c|}
\hline \multirow[t]{2}{*}{ Copolymer } & \multicolumn{4}{|c|}{ Feed ratio (mol\%) } & \multicolumn{4}{|c|}{ Solution concentration (wt\%) } \\
\hline & NIPAAm & AAc & HEMAPCL & $\mathbf{R}$ & 5 & 10 & 15 & 20 \\
\hline N88-A2 & 88 & 8 & 4 & $2: 1$ & - & + & + & + \\
\hline N88-A3 & 88 & 9 & 3 & $3: 1$ & + & + & + & + \\
\hline N88-A4 & 88 & 9.6 & 2.4 & $4: 1$ & + & + & + & + \\
\hline N82-A3 & 82 & 13.5 & 4.5 & $3: 1$ & + & + & + & + \\
\hline N94-A3 & 94 & 4.5 & 1.5 & $3: 1$ & + & + & + & + \\
\hline
\end{tabular}

Notes: +, gelation (formed hydrogel); -, precipitation (did not form hydrogel).

Abbreviations: AAc, acrylic acid; HEMAPCL, 2-hydroxylethyl methacrylate-poly(e-caprolactone); NIPAAm, N-isopropylacrylamide; R, molar ratio. 

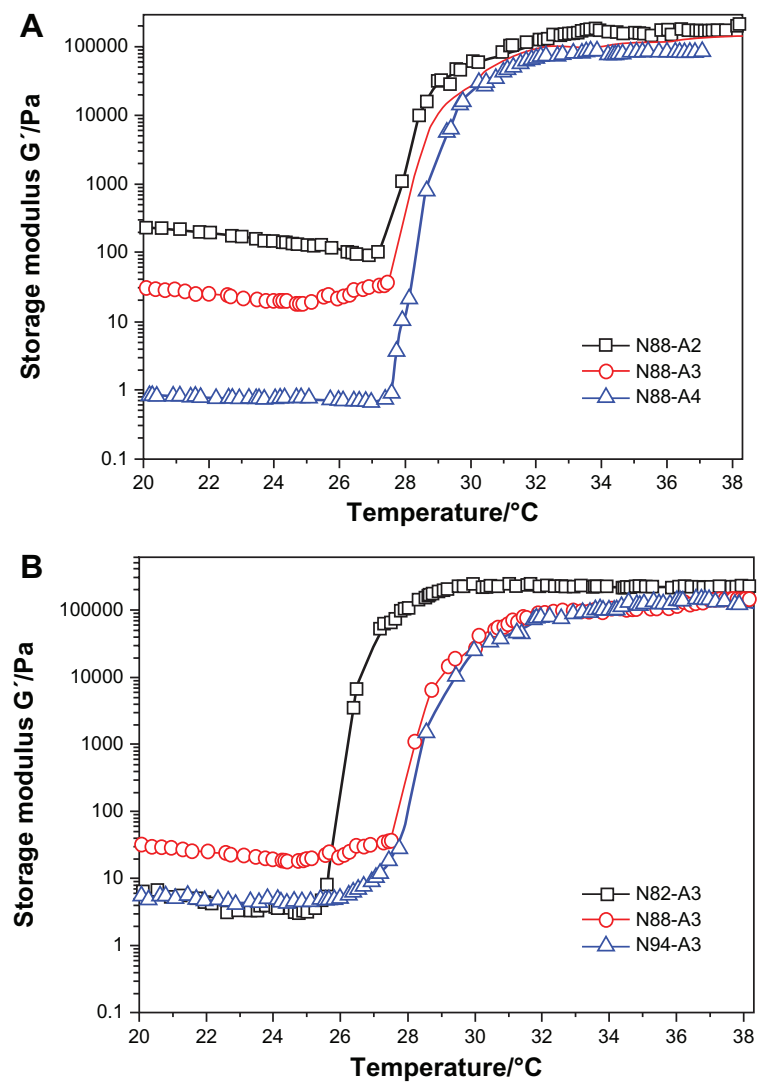

Figure 3 Storage modulus $\mathrm{G}^{\prime}$ as a function of the temperature for copolymers with the same NIPAAm content $(\mathbf{A})$ and copolymers with the same $\mathrm{R}$ ratio $(\mathbf{B})$ in a PBS solution $(\mathrm{pH}=7.4, \mathrm{I} 5 \mathrm{wt} \%)$ at a frequency of $\mathrm{I} \mathrm{Hz}$ and $1 \%$ strain.

Abbreviations: NIPAAm, N-isopropylacrylamide; PBS, phosphate-buffered saline; $\mathrm{R}$ ratio, molar ratio.

with various concentrations. Figure 5 shows the effect of temperature on the absorption of visible light $(\lambda=500 \mathrm{~nm})$ through the hydrogel solutions with different copolymer concentrations. The $\mathrm{CP}$ for each copolymer solution was obtained from the turbidity curves and was interpreted as the temperature at which the absorption of light increased up to $50 \%$ of total. Figure 5 also shows that the transition curve of the absorption is relatively sharp, so that fast phase transition occurred. The results showed no significant difference on the curves when measurement was taken with high concentrations such as $7.5 \mathrm{wt} \%$ and $10 \mathrm{wt} \%$. But reduction of the copolymer concentration (2.5 wt \%), caused the start temperature of the phase transition to increase slightly and the transition temperature interval became more narrow. This indicated that the hydrogel phase transition processed faster in the diluted solution than in the concentrated one. This phenomenon could be attributed to stretching of the polymer chains in the diluted solutions, which facilitated hydrophobic association during heating.
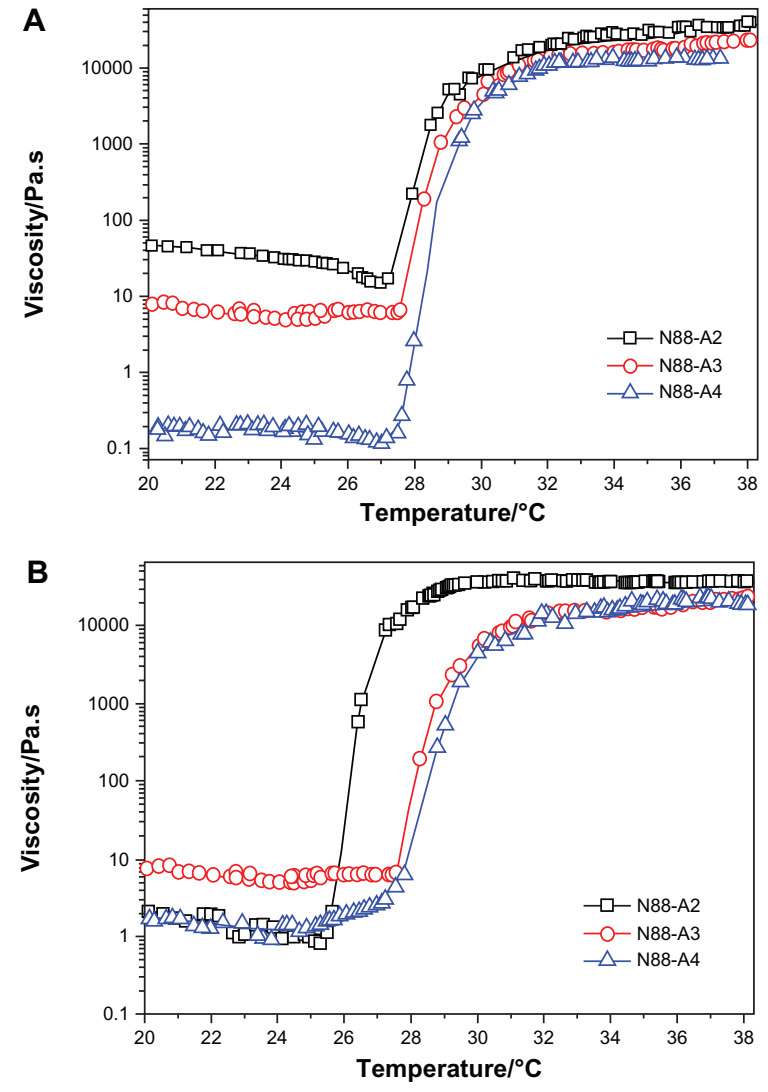

Figure 4 Viscosity $\eta$ as a function of temperature for copolymers with the same NIPAAm content (A) and copolymers with the same $\mathrm{R}$ ratio $(\mathbf{B})$ in a PBS solution $(\mathrm{pH}=7.4,15 \mathrm{wt} \%)$ at a frequency of $\mathrm{I} \mathrm{Hz}$ and $1 \%$ strain.

Abbreviations: NIPAAm, N-isopropylacrylamide; PBS, phosphate-buffered saline; $\mathrm{R}$ ratio, molar ratio.

N88-A4 copolymer was also taken as an example to illustrate the process of phase transition of NIPAAm/AAc/ HEMAPCL hydrogel and its reversibility in a PBS solution $(15 \mathrm{wt} \%)$ at $\mathrm{pH}=7.4$. The copolymer chains exhibited desirable hydrophilicity at low temperature so that the

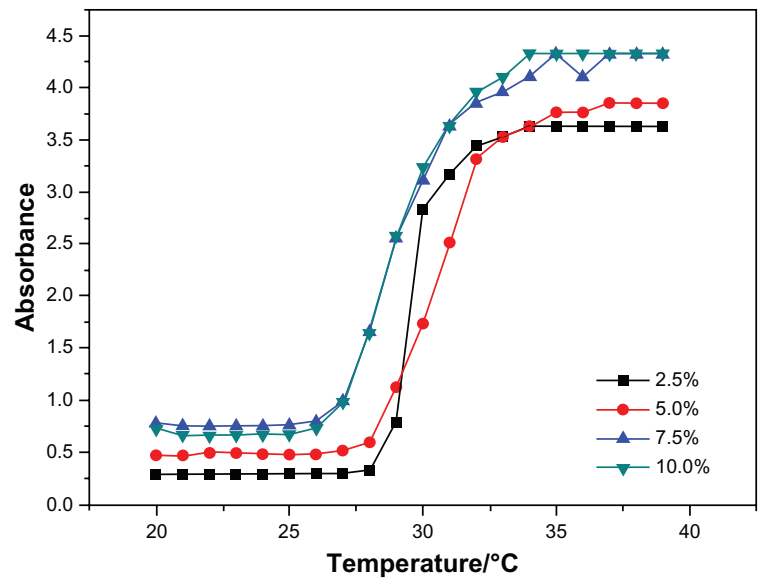

Figure 5 Cloud point determination of the N88-A4 copolymer with different polymer concentrations $(2.5,5.0,7.5,10.0 \mathrm{wt} \%)$. 
hydrogen bonding could be formed between copolymer chains and water molecules. Therefore, the copolymer was easy to dissolve in water. As shown in the first diagram of Figure 6, copolymer chains stretched freely below the transition temperature. Within this temperature range, the copolymer chains exhibited faster motion with increasing temperature while the solution showed better fluidity. This mechanism is consistent with the rheology curves in Figure 4, and explains the gentle decline of the solution viscosity curve below LCST. When the temperature was raised to the $\mathrm{CP}$, the hydrogen bonding was disrupted and the copolymer chains became partially hydrophobic and aggregated into micelles by hydrophobic interaction. At this time, the solution turned from transparent to opaque and the system exhibited the lowest viscosity. With temperature increasing, the sol-gel transition of the copolymer solutions occurred within 30 seconds by
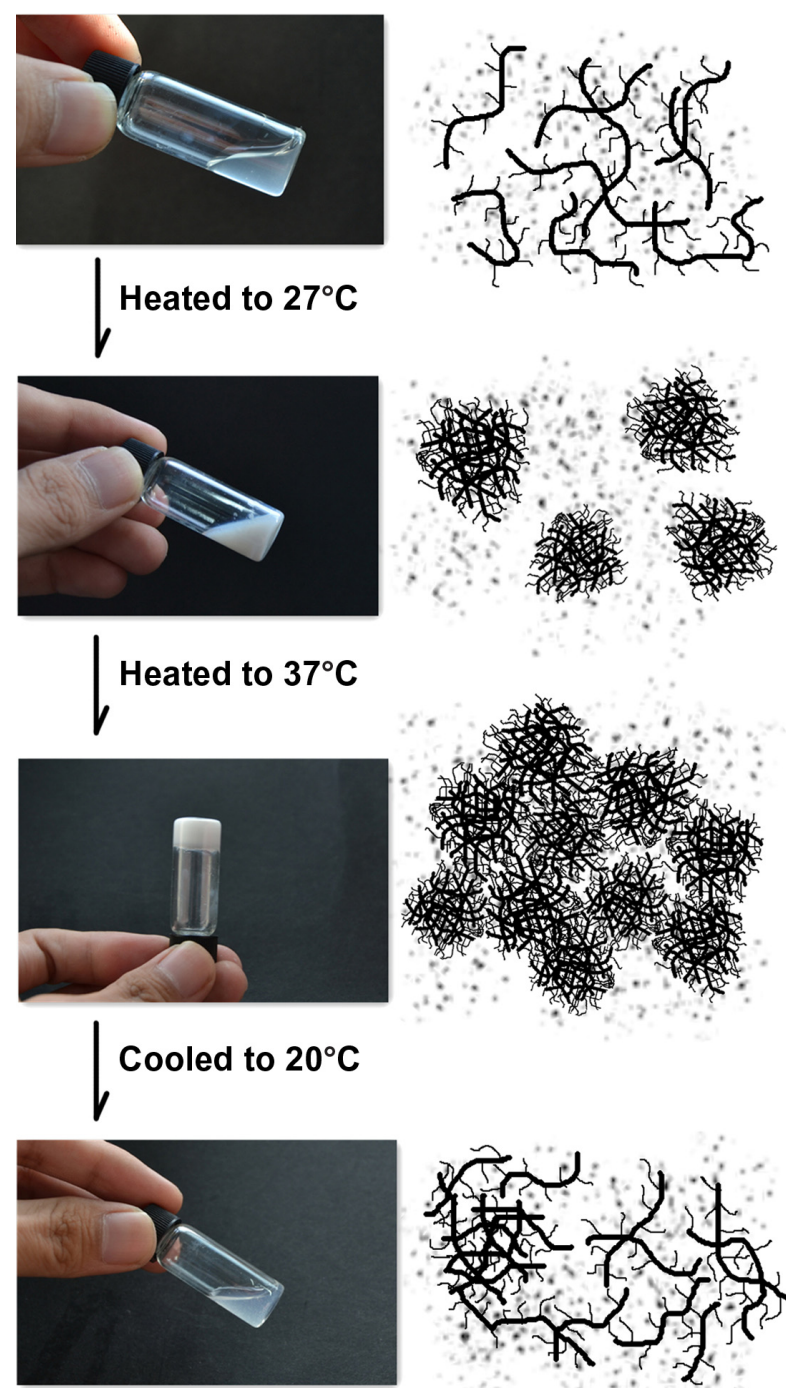

Figure 6 In-situ gelation of the N88-A4 hydrogel with 15 wt\% copolymer concentration. assembly of the micelles with PCL side-chain as physical cross-linking sites. As shown in Figure 6, it is important to point out that little water was expelled from the hydrogel when heated to $37^{\circ} \mathrm{C}$. However, the white gel turns back to transparent fluid after being cooled to room temperature due to disassembly of the tangled copolymer chains.

\section{Hydrogel property}

To investigate the property of the formed gel in terms of degradation behavior, water content and the interior morphology, N88-A2, N88-A3, and N88-A4 were selected for comparison. In Figure 7, all the three hydrogels demonstrated sustained degradation in PBS solution ( $\mathrm{pH}=7.4$ ) within 2 weeks. At the end of day 14 , all the hydrogels had a remaining weight of over $85 \%$ of their initial weight. During the first 2 days, three hydrogels underwent significant weight loss, owing to the fact that the tiny fragments on the surface of the samples flaked off and dissolved in the buffer solution. The hydrogels with the same NIPAAm content exhibited gentle degradation after 2 days. It was found that the hydrogel degradation rate was enhanced significantly when changing AAc/HEMAPCL ratio ( $R$ ratio) from 2:1 to 4:1. Because of the protonation of the AAc units, the hydrolysis of the ester bonds was accelerated, and the cross-links of PCL chains by hydrophobic interaction were released and diffused into the PBS solutions. The rupture of cross-links in the hydrogels made the remaining hydrogel networks more hydrophilic and caused the samples to dissolve at $37^{\circ} \mathrm{C}$. As a result, the higher the $\mathrm{R}$ ratio, the faster the degrading process. Figure 8 shows the hydrogel water content with different $\mathrm{R}$ ratios during degradation. All the three samples demonstrated a slight

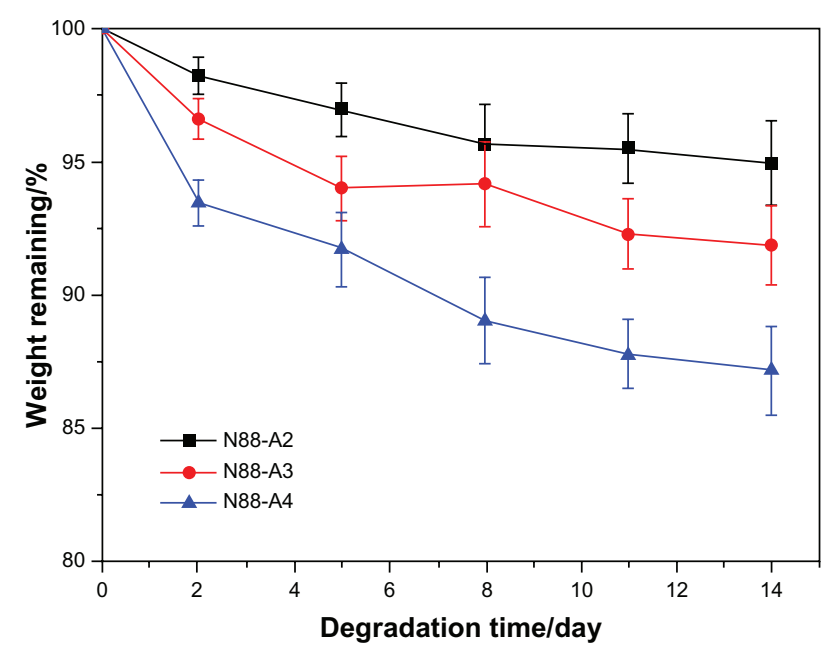

Figure 7 Degradation of N88 series copolymer hydrogels in phosphate-buffered saline at $37^{\circ} \mathrm{C}$ with respect to weight loss.

Note: Values reported are an average $n=3$, \pm standard deviation. 


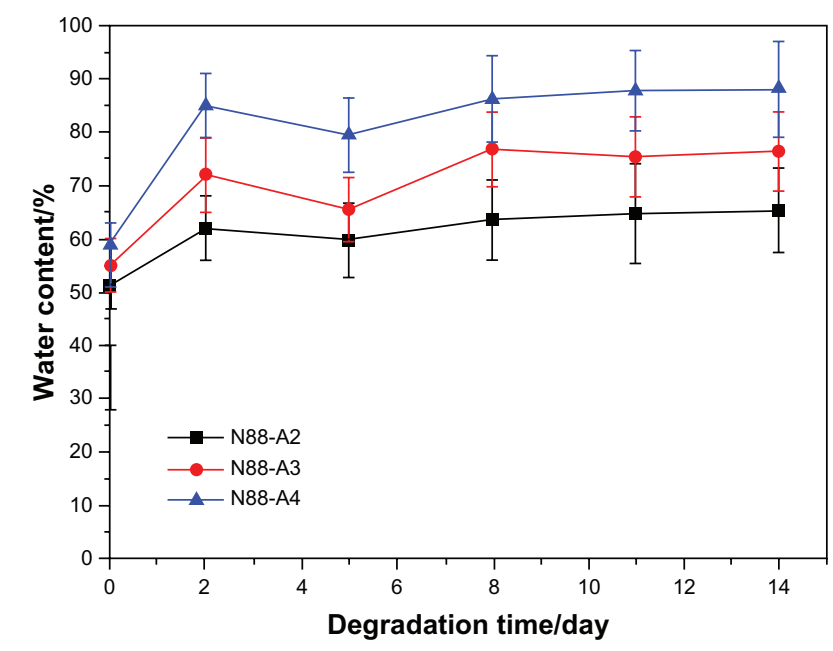

Figure 8 Water content of N88 series copolymer hydrogels during the degradation.

increase of water content within the 14 days. Comparing the water content curves of N88-A2, N88-A3, and N88-A4, $\mathrm{R}$ ratio in copolymer feed ratio significantly influenced the swelling ratio of the copolymer hydrogels. The N88-A4 hydrogel in PBS exhibited better water retention with respect to the N88-A2 hydrogel. It is supposed that, with the same NIPAAm content, a higher AAc/HEMAPCL ratio in the copolymer chains caused lower cross-link density and looser hydrogel network, further leading to stronger hydrophilicity and water absorption.

The interior morphology of these three freeze-dried hydrogels is shown in Figure 9. The hydrogels displayed a continuous and porous microscopic structure, which was related to the composition ratio of AAc/HEMAPCL.
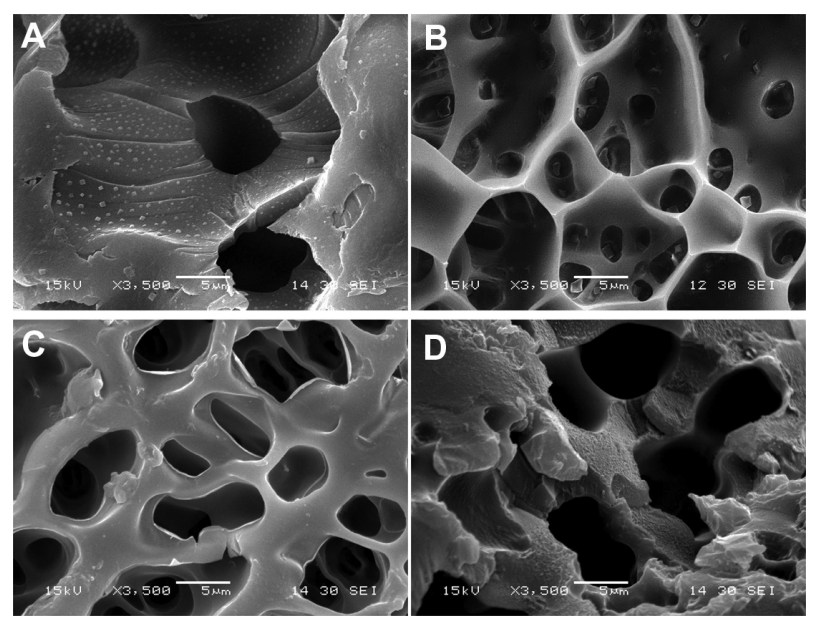

Figure 9 Scanning electron microscopy micrographs of the neat PNIPAAm (A), N88-A2 hydrogel (B), N88-A3 hydrogel (C), and N88-A4 hydrogel (D).

Abbreviation: PNIPAAm, poly( $N$-isopropylacrylamide).
The N88-A2 hydrogel had an average pore diameter of about $3 \mu \mathrm{m}$ by analyzing the pore size in Figure 9, while the N88-A4 hydrogel was around $6 \mu \mathrm{m}$. The difference in pore size indicated that higher AAc/HEMAPCL ratio could result in the formation of larger pores and looser network structure of hydrogel, likely due to a decline in the crosslinking density with the decrease in the HEMAPCL units. It could also indicate that hydrogel with big pores might demonstrate high water content and fast degradation, which is consistent with the statement above. To compare the impact of copolymerization on microscopic morphology, the microscopic structure of pure PNIPAAm was shown in Figure 9A as well, demonstrating that copolymerization endowed the hydrogel networks with better connectivity and tighter structure.

\section{Copolymer bioconjugation of collagen}

As the most suitable copolymer for injection, bioconjugation of the N88-A4 with type I collagen was conducted by introducing the reactive group NHS to the copolymer backbone using EDC. The reaction process is shown in Scheme 2. The intermediate product with NHS group was confirmed by ${ }^{1} \mathrm{H}$ NMR spectroscopy (Figure 10), by which the characteristic proton peak of NHS groups was demonstrated at about $2.9 \mathrm{ppm}$. The conjugation of type I collagen with N88-A4 copolymer was confirmed by FTIR spectroscopy (Figure 11). Copolymer without collagen showed characteristic NHS group peaks at 1740 and $1780 \mathrm{~cm}^{-1}$ respectively (Figure 11, top curve), while these two peaks disappeared in the copolymer conjugated with collagen (Figure 11, bottom curve), indicating that collagen had reacted as a participant with the NHS groups successfully. The conjugated copolymer exhibited similar characteristics to the initial N88-A4 copolymer. For instance, the composite was still soluble at low temperature and could be injected through a 26 gauge needle with a concentration of $15 \mathrm{wt} \%$. Opaque hydrogel was formed as well when the hydrogel solution was heated to $37^{\circ} \mathrm{C}$ and the collagen incorporation slightly increased the LCST compared with the initial N88-A4.

\section{Cytotoxicity assay}

CCK-8 assay was performed to investigate the cytotoxicity of the hydrogels. The copolymers with the same NIPAAm content were used as comparison of the bioconjugated N88-A4 copolymer, as well as pure PNIPAAm. The impact of the copolymer feed ratio on the proliferation of BMSCs was studied (Figure 12). The results demonstrated that no 


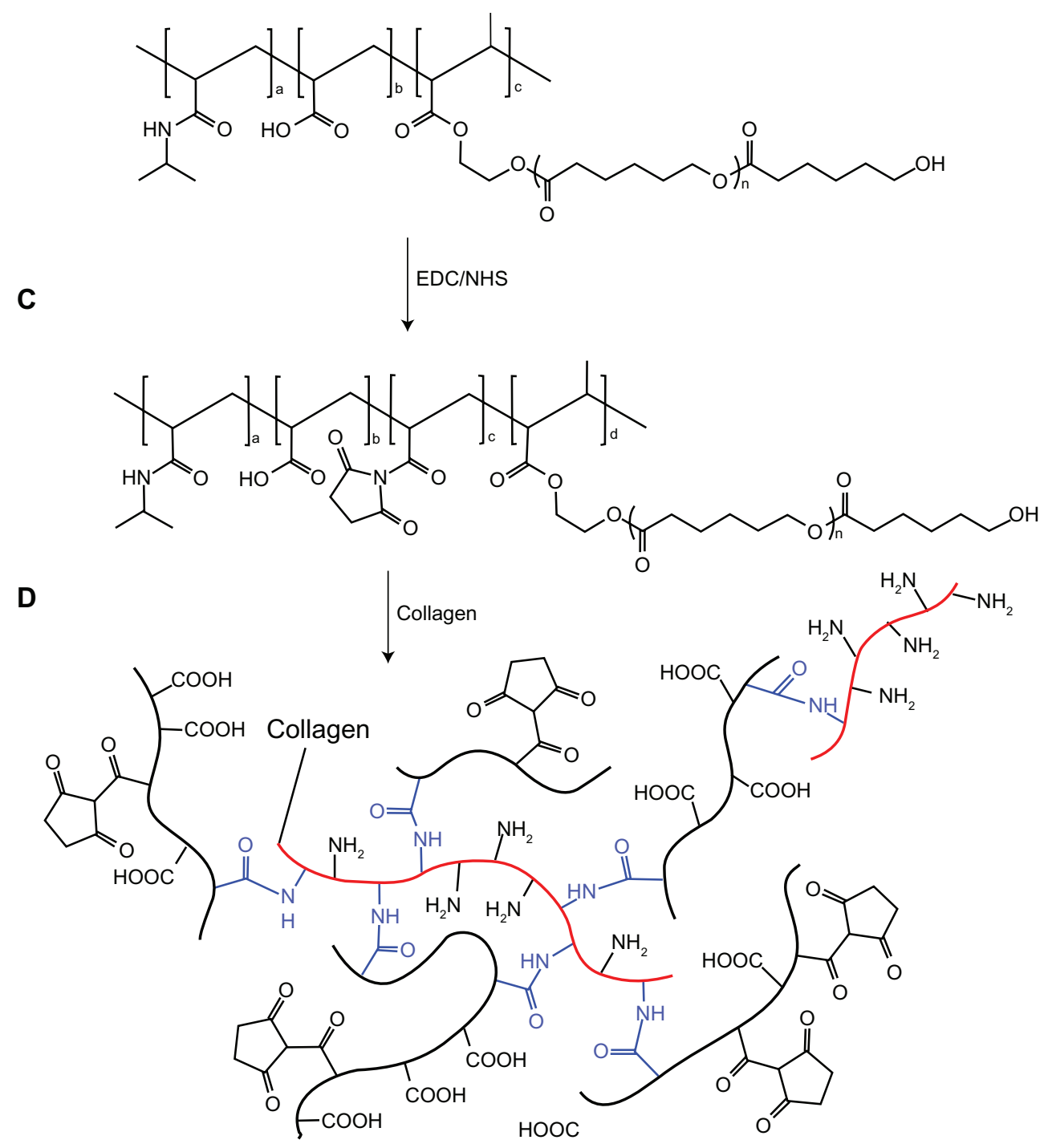

Scheme 2 Conjugation of N88-A4 copolymer with type I collagen.

Abbreviations: EDC, I-ethyl-3-(3-dimethyl-aminopropyl)-I-carbodiimide hydrochloride; NHS, N-hydroxysuccinimide.

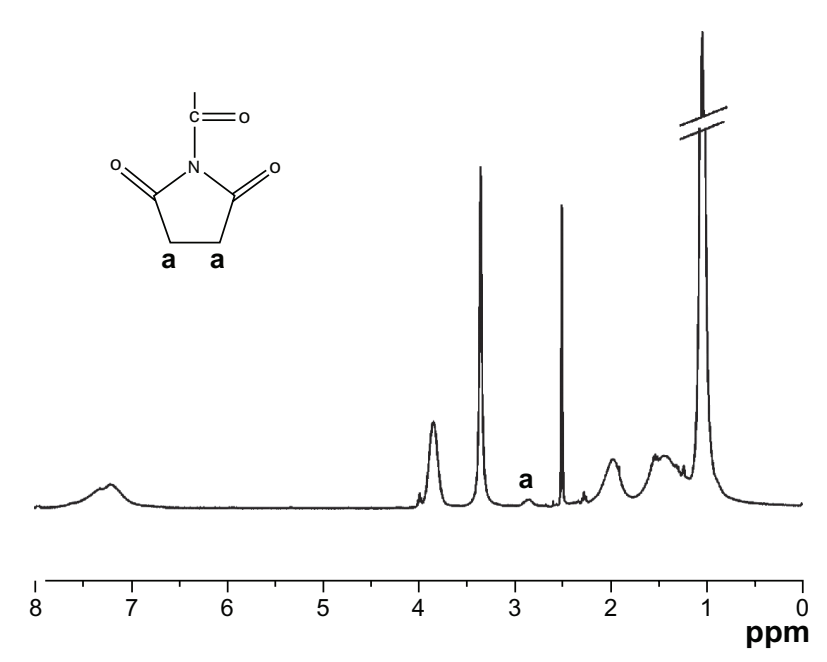

Figure 10 Proton nuclear magnetic resonance spectrum of N88-A4 copolymer reacted with $\mathrm{N}$-hydroxysuccinimide.

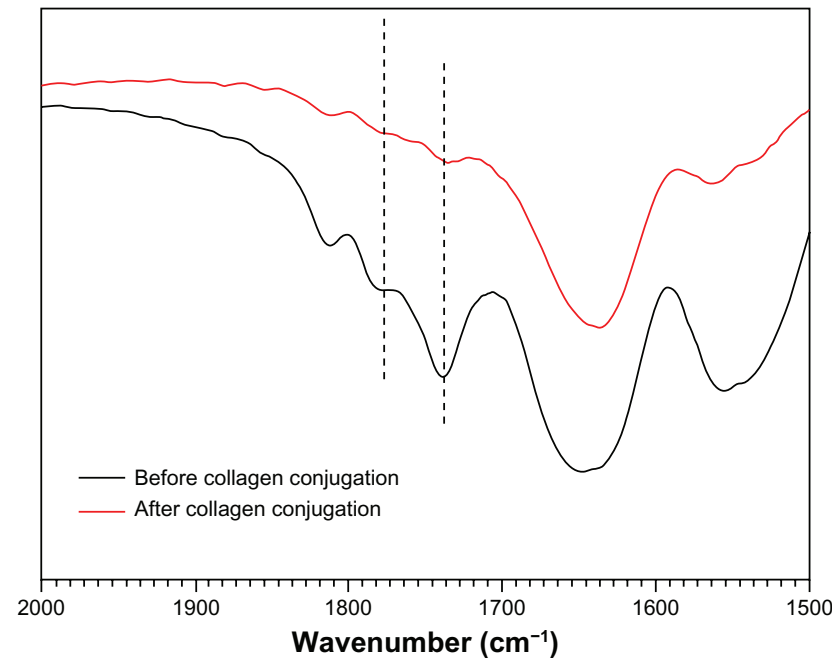

Figure II Fourier transform infrared spectra of N88-A4 copolymer with $\mathrm{N}$-hydroxysuccinimide group before and after collagen conjugation. 


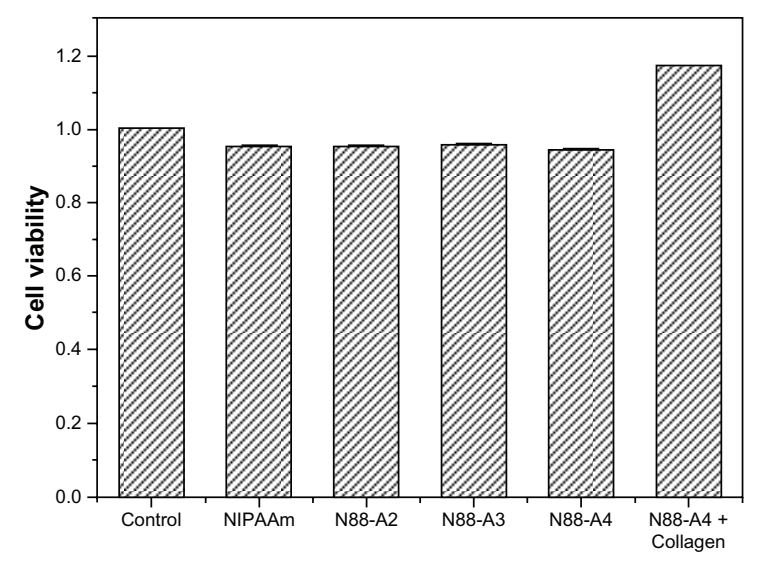

Figure 12 Cytotoxicity studies of the copolymer with different $\mathrm{R}$ ratio and PNIPAAm after 96 hours culture.

Notes: The standard errors of NIPAAm, N88-A2, N88-A3, N88-A4, and N88-A4 with collagen are $0.0004,0.0012,0.0001,0.0016$, and 0.0003 , respectively. Abbreviations: NIPAAm, $\mathrm{N}$-isopropylacrylamide; PNIPAAm, poly $(\mathrm{N}$-isopropylacrylamide); $\mathrm{R}$ ratio, molar ratio.

significant decrease occurred in the cell viability after 3 days culture when the $\mathrm{R}$ ratio of the feed ratio varied from $2: 1$ to $4: 1$. At least $95 \%$ cells remained alive at the end of 96 hours and no significant difference was observed between these three copolymers. Similar cell density was detected in the culture medium with supplementation of neat NIPAAm as well. As expected, the collagen-conjugated copolymer demonstrated the highest cell viability which implied favorable compatibility. As a widely used bioactive factor for tissue engineering applications, collagen offers a good adhesive surface that promotes cellular attachment, proliferation, and expansion. ${ }^{37}$ As a result, all the copolymers were found to have no obvious cytotoxicity, and bioconjugation could enhance the cell viability, which would render this material an ideal candidate for injectable tissue applications.

\section{Conclusion}

Thermosensitive, injectable, and degradable copolymer with high strength and low degradation rate was synthesized, based on NIPAAm, AAc, and macromer HEMAPCL, with different feed ratio. The copolymer was soluble at low temperature and experienced sol-gel transition within 30 seconds when heated above LCST. The hydrogels with higher NIPAAm content exhibited higher LCST, but no evidence was found that NIPAAm content had a significant influence on copolymer solution viscosity. However, the increase of the $\mathrm{R}$ ratio reduced the solution viscosity remarkably but raised the LCST and the storage modulus of the hydrogel. Therefore, N88-A4 was considered the best candidate for injection for its appropriate properties as copolymer and hydrogel. The formed gel with higher AAc/HEMAPCL ratio also showed higher water content and degradation rate. Degradation experiment revealed that it took at least 14 days for the hydrogels to achieve a weight loss less than $15 \%$. Bioconjugation was also performed between N88-A4 and collagen by EDC/NHS crosslinking. Cell viability test in vitro demonstrated that poly(NIPAAm- $\mathrm{co}$-AAc-co-HEMAg-PCL) was noncytotoxic for stem cell encapsulation, and the biocompatibility of its hydrogel could be improved greatly when type I collagen was bioconjugated. As a result, these properties endowed the copolymer with huge potential to be applied as intelligent scaffold in stem cell therapy for myocardial infarction.

\section{Acknowledgments}

This research was supported by the Fundamental Research Funds for the Central Universities (WD0913008, WD1014017), "Shu Guang” Project of Shanghai Municipal Education Commission, the Natural Science Foundation of Shanghai (11ZR1409200), the National Natural Science Foundation of China (51103041), the Scientific Research Foundation for the Returned Overseas Chinese Scholars State Education Ministry, Shanghai Leading Academic Discipline Project (B502), Shanghai Key Laboratory Project (08DZ2230500), and Changjiang Scholars and Innovative Research Team in University (IRT0825).

\section{Disclosure}

The authors report no conflicts of interest in this work.

\section{References}

1. Laflamme MA, Murry CE. Heart regeneration. Nature. 2011;473(7347): 326-335.

2. Anversa P. Life and death of cardiac stem cells: a paradigm shift in cardiac biology. Circulation. 2006;113(11):1451-1463.

3. Wu K, Liu Y, Zhou B, et al. Cellular therapy and myocardial tissue engineering: the role of adult stem and progenitor cells. Eur $J$ Cardiothorac Surg. 2006;30(5):770-781.

4. Siminiak T. Autologous skeletal myoblast transplantation for the treatment of postinfarction myocardial injury: Phase I clinical study with 12 months of follow-up. Am Heart J. 2004;148(3):531-537.

5. Jopling C, Sleep E, Raya M, et al. Zebrafish heart regeneration occurs by cardiomyocyte dedifferentiation and proliferation. Nature. 2010;464(7288):606-609.

6. Yeo C, Mathur A. Autologous bone marrow-derived stem cells for ischemic heart failure: REGENERATE-IHD trial. Regen Med. 2009; 4(1):119-127.

7. Martin-Rendon E, Brunskill SJ, Hyde CJ, et al. Autologous bone marrow stem cells to treat acute myocardial infarction: a systematic review. Eur Heart J. 2008;29(15):1807-1818.

8. Chen S, Fang W, Ye F, et al. Effect on left ventricular function of intracoronary transplantation of autologous bone marrow mesenchymal stem cell in patients with acute myocardial infarction. Am J Cardiol. 2004;94(1):92-95.

9. Mooney DJ, Vandenburgh H. Cell delivery mechanisms for tissue repair. Cell Stem Cell. 2008;2(3):205-213. 
10. Ott H, Kroess R, Bonaros $\mathrm{N}$, et al. Intramyocardial microdepot injection increases the efficacy of skeletal myoblast transplantation. Eur $J$ Cardiothorac Surg. 2005;27(6):1017-1021.

11. Yu L, Ding J. Injectable hydrogels as unique biomedical materials. Chem Soc Rev. 2008;37(8):1473.

12. Martens TP, Godier AFG, Parks JJ, et al. Percutaneous cell delivery into the heart using hydrogels polymerizing in situ. Cell Transplant. 2009;18(3):297-304.

13. Dubois G, Segers VFM, Bellamy V, et al. Self-assembling peptide nanofibers and skeletal myoblast transplantation in infarcted myocardium. J Biomed Mater Res B Appl Biomater. 2008;87(1):222-228.

14. Van Tomme SR, Storm G, Hennink WE. In situ gelling hydrogels for pharmaceutical and biomedical applications. Int J Pharm. 2008; 355(1-2):1-18.

15. Paula M, Goissis G, Martins VCA. Rheological behavior of anionic collagen injectable gels in the presence of rhamsan for plastic surgery applications. J Mater Sci Mater Med. 2007;18(9):1683-1690.

16. Ji QX, Deng J, Xing XM, et al. Biocompatibility of a chitosan-based injectable thermosensitive hydrogel and its effects on dog periodontal tissue regeneration. Carbohydr Polym. 2010;82(4):1153-1160.

17. Sakai S, Hirose K, Taguchi K, et al. An injectable, in situ enzymatically gellable, gelatin derivative for drug delivery and tissue engineering. Biomaterials. 2009;30(20):3371-3377.

18. Jeon O, Bouhadir KH, Mansour JM, et al. Photocrosslinked alginate hydrogels with tunable biodegradation rates and mechanical properties. Biomaterials. 2009;30(14):2724-2734.

19. Jin R, Moreira Teixeira LS, Krouwels A, et al. Synthesis and characterization of hyaluronic acid-poly(ethylene glycol) hydrogels via Michael addition: an injectable biomaterial for cartilage repair. Acta Biomater. 2010;6(6):1968-1977.

20. Sano K-I, Kawamura R, Tominaga T, et al. Thermoresponsive microtubule hydrogel with high hierarchical structure. Biomacromolecules. 2011;12(5):1409-1413.

21. Yu L, Zhang Z, Zhang H, et al. Mixing a sol and a precipitate of block copolymers with different block ratios leads to an injectable hydrogel. Biomacromolecules. 2009;10(6):1547-1553.

22. Gong CY, Dong PW, Shi S, et al. Thermosensitive PEG-PCL-PEG hydrogel controlled drug delivery system: sol-gel-sol transition and in vitro drug release study. J Pharm Sci. 2009;98(10):3707-3717.

23. Fusco S. Perspectives on: PEO-PPO-PEO triblock copolymers and their biomedical applications. J Bioact Compat Polym. 2006;21(2): $149-164$.
24. Fitzpatrick SD, Jafar Mazumder MA, Lasowski F, et al. PNIPAAmgrafted-collagen as an injectable, in situ gelling, bioactive cell delivery scaffold. Biomacromolecules. 2010;11(9):2261-2267.

25. Rzaev ZMO, Dinçer S, Pişkin E. Functional copolymers of $\mathrm{N}$-isopropylacrylamide for bioengineering applications. Prog Polym Sci. 2007;32(5):534-595.

26. Solis FJ, Weiss-Malik R, Vernon B. Local monomer activation model for phase behavior and calorimetric properties of LCST gel-forming polymers. Macromolecules. 2005;38(10):4456-4464.

27. Cui Z, Lee BH, Pauken C, et al. Degradation, cytotoxicity, and biocompatibility of NIPAAm-based thermosensitive, injectable, and bioresorbable polymer hydrogels. J Biomed Mater Res A . 2011;98A(2): $159-166$.

28. Henderson E, Lee BH, Cui Z, et al. In vivoevaluation of injectable thermosensitive polymer with time-dependent LCST. J Biomed Mater Res A. 2009;90A(4):1186-1197.

29. Ma Z, Nelson DM, Hong Y, et al. Thermally responsive injectable hydrogel incorporating methacrylate-polylactide for hydrolytic lability. Biomacromolecules. 2010;11(7):1873-1881.

30. Dai W, Zhang Y, Du Z, et al. The pH-induced thermosensitive poly (NIPAAm-co-AAc-co-HEMA)-g-PCL micelles used as a drug carrier. J Mater Sci Mater Med. 2010;21(6):1881-1890.

31. Gong C, Shi S, Dong P, et al. Synthesis and characterization of PEG-PCLPEG thermosensitive hydrogel. Int J Pharm. 2009;365(1-2):89-99.

32. Cao Z, Liu W, Gao P, et al. Toward an understanding of thermoresponsive transition behavior of hydrophobically modified N-isopropylacrylamide copolymer solution. Polymer. 2005;46(14):5268-5277.

33. Matsuyama A, Tanaka F. Theory of solvation-induced reentrant phase separation in polymer solutions. Phys Rev Lett. 1990;65(3): $341-344$.

34. Garbern JC, Hoffman AS, Stayton PS. Injectable pH- and temperatureresponsive poly(N-isopropylacrylamide-co-propylacrylic acid) copolymers for delivery of angiogenic growth factors. Biomacromolecules. 2010;11(7):1833-1839.

35. Chen Q-Z, Bismarck A, Hansen U, et al. Characterisation of a soft elastomer poly(glycerol sebacate) designed to match the mechanical properties of myocardial tissue. Biomaterials. 2008;29(1):47-57.

36. Cilurzo F, Selmin F, Minghetti P, et al. Injectability evaluation: an open issue. AAPS Pharm Sci Tech. 2011;12(2):604-609.

37. Chen R-N, Wang G-M, Chen C-H, et al. Development of N,O(carboxymethyl)chitosan/collagen matrixes as a wound dressing. Biomacromolecules. 2006;7(4):1058-1064.
International Journal of Nanomedicine

\section{Publish your work in this journal}

The International Journal of Nanomedicine is an international, peerreviewed journal focusing on the application of nanotechnology in diagnostics, therapeutics, and drug delivery systems throughout the biomedical field. This journal is indexed on PubMed Central,

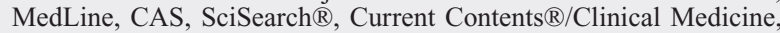

\section{Dovepress}

Journal Citation Reports/Science Edition, EMBase, Scopus and the Elsevier Bibliographic databases. The manuscript management system is completely online and includes a very quick and fair peer-review system, which is all easy to use. Visit http://www.dovepress.com/ testimonials.php to read real quotes from published authors. 